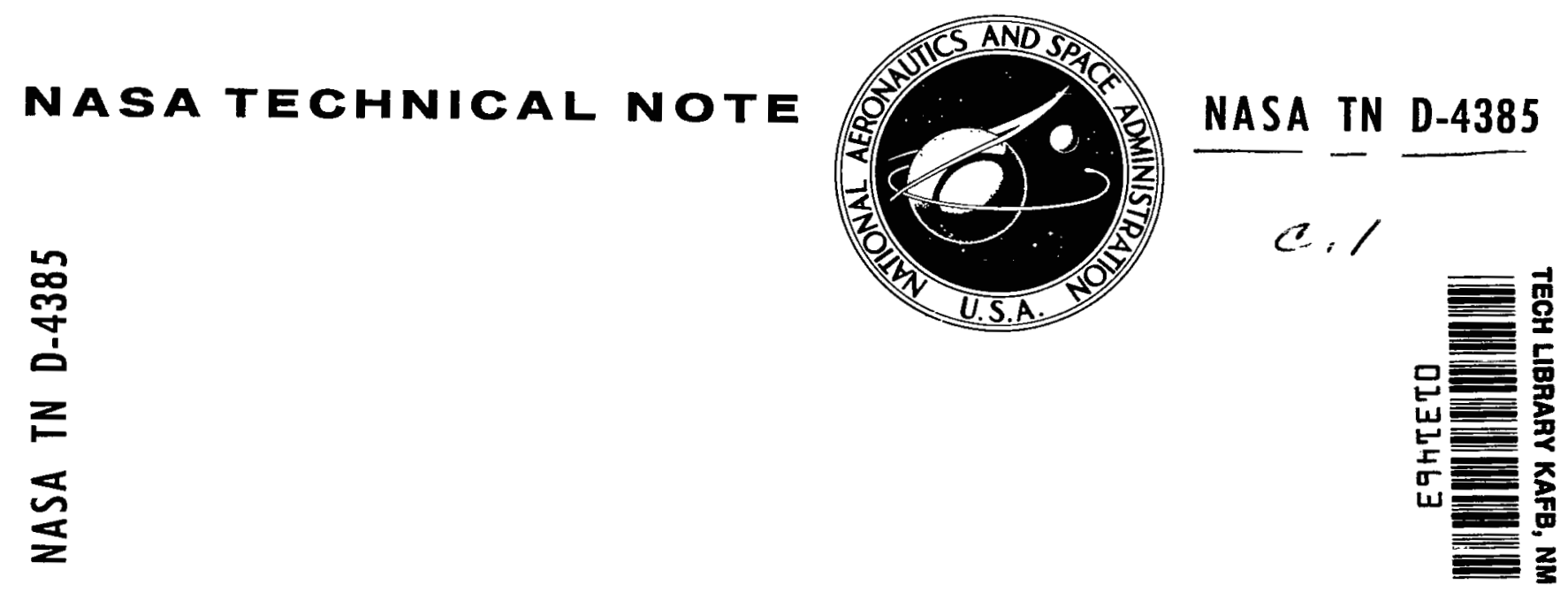

LOAN COPY: RETURN TO

AFWL (WLIL-2)

KIRTLAND AFB, N MEX

\title{
CORRELATION OF TRANSIENT SPECTRA WITH PERFORMANCE IN COAXIAL PLASMA GUNS
}

by Charles J. Michels and Henry J. Hettel

Lewis Research Center

Cleveland, Obio

NATIONAL AERONAUTICS AND SPACE ADMINISTRATION - WASHINGTON, D. C. - FEBRUARY 1968 


\section{CORRELATION OF TRANSIENT SPECTRA WITH PERFORMANCE}

\section{IN COAXIAL PLASMA GUNS}

By Charles J. Michels and Henry J. Hettel

Lewis Research Center

Cleveland, Ohio

\section{NATIONAL AERONAUTICS AND SPACE ADMINISTRATION}




\title{
CORRELATION OF TRANSIENT SPECTRA WITH PERFORMANCE
}

\author{
IN COAXIAL PLASMA GUNS \\ by Charles J. Michels and Henry J. Hettel \\ Lewis Research Center
}

\section{SUMMARY}

The time-varying spectra of an argon plasma in a coaxial gun were measured. Two gun geometries were investigated, both with argon propellant. The transient spectra were obtained by viewing the plasma spectra in the exit plane of a polychromator with an electronic image converter camera used as a streak camera. Frame and streak camera views and magnetic probes were also used to study the discharges occurring in the guns. The transient spectrum of each gun was completely different. The geometry which exhibits relatively clean argon spectra showed good performance. It operated internally crowbarred. The performance correlates well with both earlier theory and experiments and extends previous data.

In contrast, the geometry which exhibited contaminant spectra showed poorer performance which does not agree with theory or past experimental data. This geometry operated in the multiple-moving-discharges mode. The discharge spectra showed no argon lines, and the contaminant lines were those from a pyrex gas baffle just upstream of the gas ports. The influence of the gas baffle on performance accounts for discrepancies with earlier data (both experimental and theoretical).

The two different geometries of the guns served to demonstrate the usefulness of transient spectra diagnostics as an added tool in ascertaining when theory can correctly be applied to a given gun.

A description of a two-channel transient voltage digitizer is given. The digitizer is used to record dynamically gun voltage and current at the rate of 5 million samples per second. It digitizes these samples and punches them on paper tape for data reduction by a conventional high-speed computer. 


\section{INTRODUCTION}

The spectrum of the discharge of a coaxial plasma gun is a diagnostic tool useful in correlating experimental results with a theoretical model. The spectrum verifies qualitatively the degree that contaminants are involved in the discharge. Time-integrated spectra (for 25 superimposed shots) were described by Michels and Johansen in reference 1, and contaminants were noted. It could not be determined from these measurements when the contaminants occurred during a shot. The present report describes the time-varying spectrum as the discharge moves past a viewing port in the gun barrel during a single shot.

Two geometries were investigated; both used argon propellant. One geometry was operated noncrowbarred and the other self-crowbarred ${ }^{1}$. The spectra were taken only for the injected mass that gave peak gun efficiency. The viewing station for each gun was chosen to observe sheets with maximum luminosity, uniform velocity, and good definition.

The theory for predicting kinetic efficiency of gun exhaust and exhaust velocity is given in references 1 and 2 . It employs the snowplow model and allows for variable mass distribution along the gun barrel, as well as for various losses from the plasma. The theory indicates the important parameters for efficient gun design. One such parameter is the nondimensional mass loading parameter. This parameter is proportional to the mass swept up in a shot. It was found in reference 3 that theory and experiment could best be compared by plotting the plasma velocity and the kinetic efficiency of the gun as functions of this mass loading parameter. Operating characteristics of the guns used in the present experiments are similarly described in the present report.

Frame and streak cameras and magnetic probes were also used to study the discharge at the station where time-resolved spectra were taken.

In the earlier investigations (refs. 1 to 3 ), the gun experimental performance was obtained by manual data processing of oscilloscope trace photographs. This procedure was tedious and time consuming and was subject to errors in reading the oscilloscope traces. In this investigation the data were dynamically digitized and later processed automatically. The transient digitizer is described in the appendix.

${ }^{1}$ Self-crowbarring refers to the formation of a secondary discharge at the breech at some time after initiation of the main discharge. The crowbar discharge remains at the breech during the shot. This process is discussed in detail in refs. 1 to 4 . 


\section{APPARATUS}

\section{Capacitor Bank}

The guns described herein were energized by a capacitor bank consisting of 11 identical sections. These sections were switched simultaneously through cabling to the coaxial plasma gun. Each section consists of two capacitors (1. $1 \mu \mathrm{F}$ each), a GL-7703 ignitron switch, and four parallel coaxial cables. A partial view of the bank is shown in figure 1. The 10 kilojoule bank has a resistance of 3.8 milliohms and an inductance of

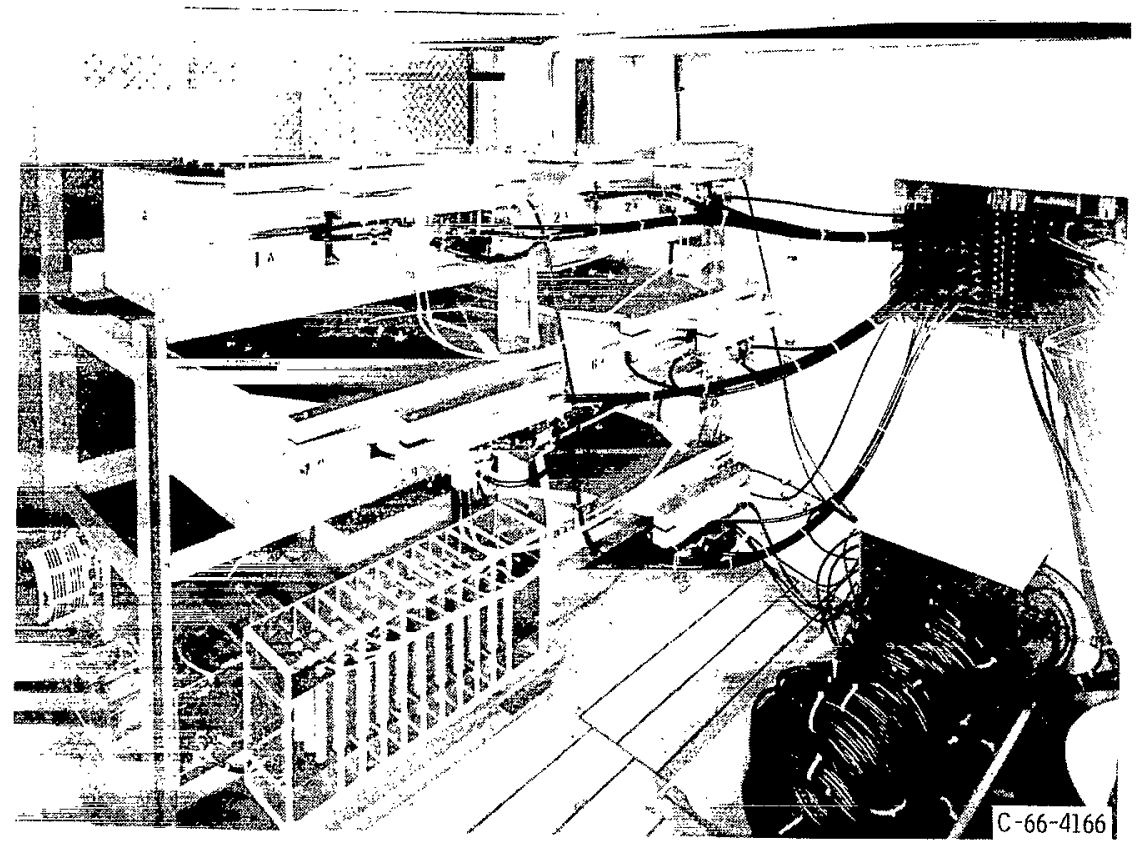

Figure 1. - Capacitor bank, 10 kilojoule.

14 nanohenries. The trigger system is as described in reference 5 for an earlier model bank. The new bank has a low-inductance ignitron holder that employs a modification of a technique discussed in reference 6 . It uses insulating oil and thus allows reducedspacing coaxial geometry. This modification lowers the assembly inductance and increases the reliability of the switch. 


\section{Gun Geometries}

The coaxial gun and the manner in which it is connected to the bank cables are shown in figure 2. The electrodes of each of the guns are made of oxygen-free highconductivity copper. At the breech of the gun is a Vycor insulator and a gun header assembly. The header connects the gun electrodes through a parallel-plate transmission line to the capacitor bank cables.

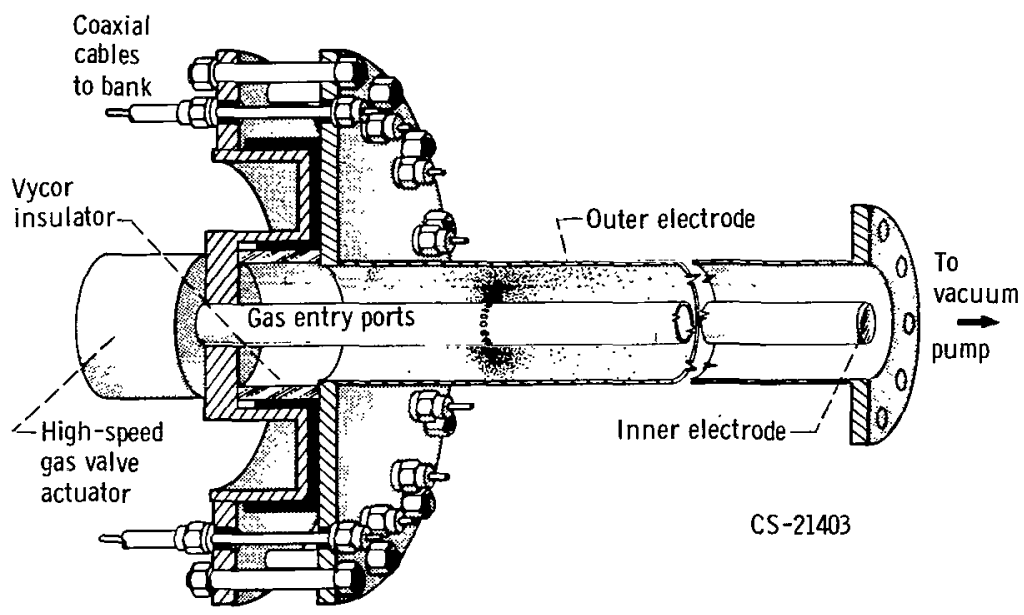

Figure 2. - Coaxial plasma gun.

A short-duration puff of argon gas was admitted into the evacuated gun annulus. It was introduced through ports in the center electrode by a fast-acting mechanical gas valve. The duration of the gas puff was set experimentally at $100 \mathrm{microseconds.} \mathrm{The}$ mass per puff was controlled by the gas pressure in the valve plenum. An air-operated hammer provided the controlled blow to actuate the valve stem.

The dimensions and electrical characteristics of the two gun geometries investigated are given in figure 3. Both geometries used the same electrode radius (radius ratio of about 3). The noncrowbarred geometry incorporated a pyrex gas baffle just upstream of the gas ports to prevent a secondary discharge at the breech. Probe station locations 1 to 4 are shown in figure 3. In the self-crowbarred geometry a corona-inhibitor ring covered a corner protruding in the breech. This ring delayed the time of selfcrowbarring. Also shown in figure 3 are the viewing windows, spaced approximately the same distance from the initial location of the moving discharge in each gun. The electrical characteristics are also shown in figure 3 and were used in computing the theoretical performance. 

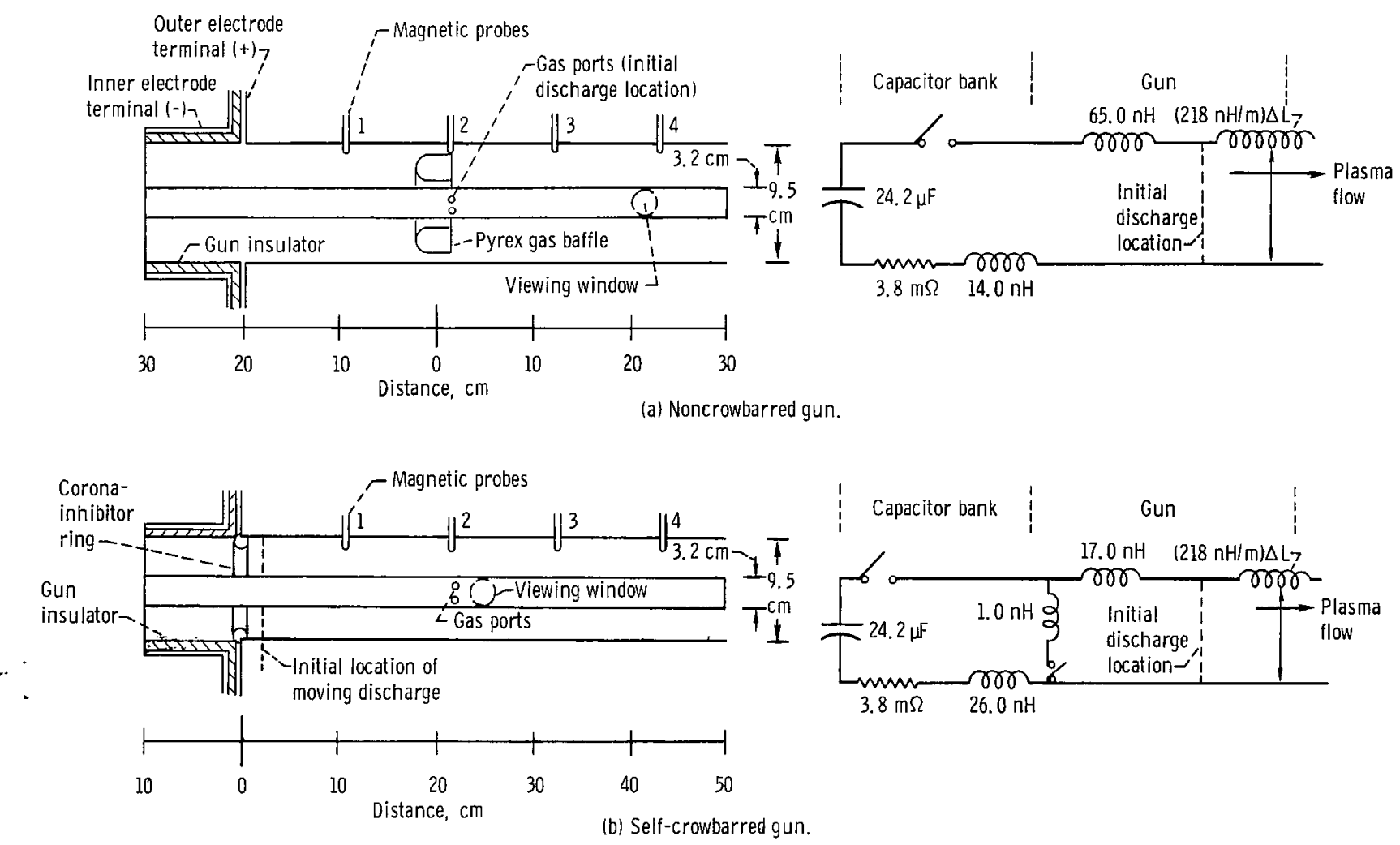

Figure 3. - Gun geometries and electrical characteristics. 


\section{Instrumentation}

Plasma energy and velocity. - Gun exhaust energy was measured by means of the temperature rise of a calorimeter cup located 30 centimeters downstream of the gun. The temperature rise was recorded on a millivolt strip-chart recorder. The calorimeter cup (15-cm diam.) was constructed to reduce ablation errors and to absorb the beam energy efficiently.

Probes for the measurement of azimuthal magnetic field were inserted in the gun annulus, 11.5 centimeters apart, staggered along the gun axis (at stations 1 to 4 in both geometries) so as not to affect the plasma sheet. Time of flight of the magnetic front between adjacent probe stations determined the front velocity. The magnetic probes had four-turn coils, solenoidally wound about a 0.127-centimeter-(0.050-in. -) diameter coil form and encased in a Vycor protector tube. The signals were transmitted by coaxial cables, terminated, passively integrated (time constant, $10 \mu \mathrm{sec}$ ), and recorded on an oscilloscope. The magnetic probes are shown in figure 4, along with other instrumentation.

Gun voltage and current. - A method of transient-gun-voltage measurement was developed. Voltage signals were sent to a transient digital recorder in a screen room 30 meters distant. Two voltage probes are shown in figure 4. One is connected to each of the gun header terminals. The dual-probe method of voltage measurement employs a

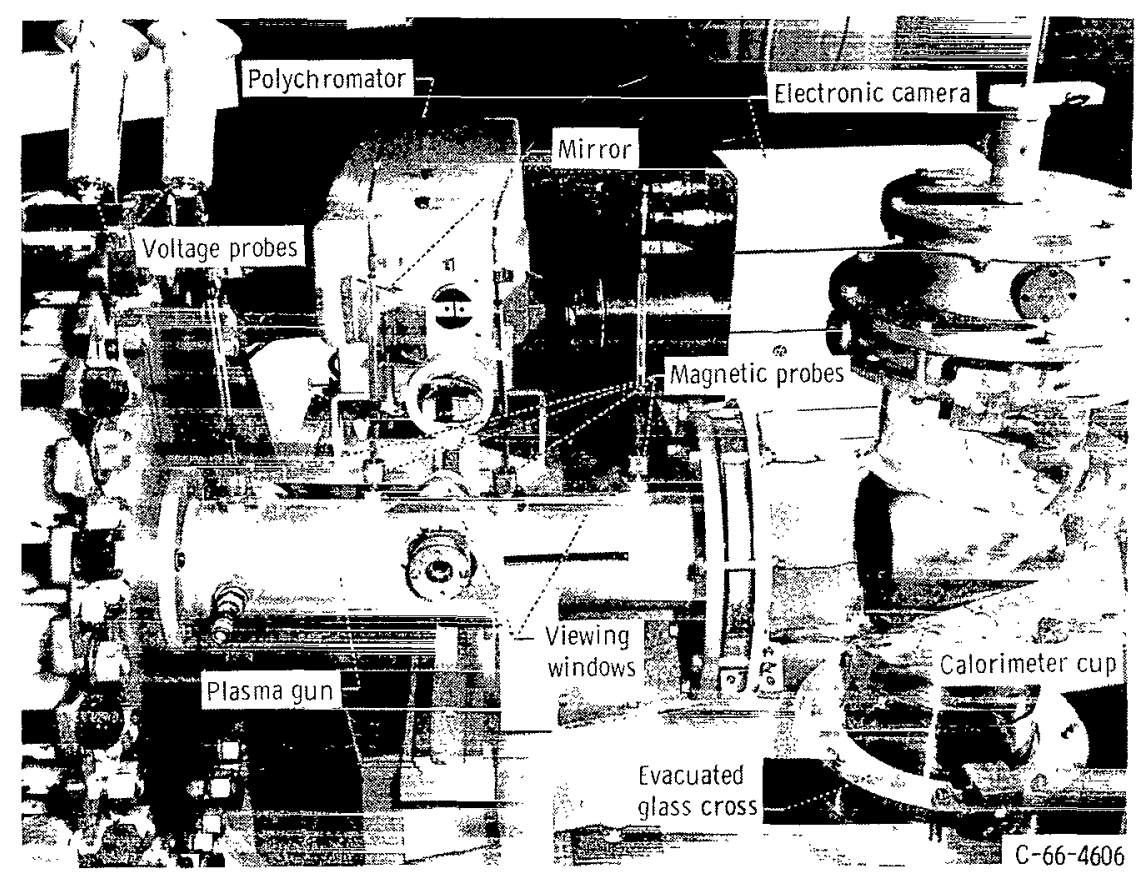

Figure 4. - Apparatus for measuring time-varying plasma spectra. 
technique discussed by Moses and Korneff in reference 7. The technique was simplified in that the auxiliary pickup coil used in reference 7 was not needed. In the present experiment, care was taken to balance dynamically each amplifier (through internal adjustments), to dress and twist all signal leads, and to filter the power source. This process provided sufficient common-mode signal rejection and balance so that the added technique of a bucking coil was not needed.

Resistive divider probes (100 M $\Omega$ ) were employed. The shield terminals of both probes were not connected at the gun in order to prevent circulating currents from occurring in the shields. The shield connection of both probes was made at the screen room near the recorder. Both probe outputs were connected to a difference amplifier near the gun. The low-impedance push-pull output of the amplifier was connected by means of a twisted pair of coaxial cables to a similar difference amplifier in the screen room. The single-ended output of this amplifier was connected to a gain-adjusting amplifier and then to the transient digital recorder.

The dual-probe technique electrically subtracts the unwanted common-mode signal portion from the "read" voltage signal. Cascaded difference amplifiers perform the subtraction. Commercially available equipment was used.

In figure 5 , the dual-probe traces are compared with waveforms obtained simultaneously by using a capacitive divider and a surge oscilloscope near the gun. A sharp voltage waveform (rise time, $<0.1 \mu \mathrm{sec}$ ) does cause some amplifier ringing, as illustrated in figures $5(\mathrm{a})$ and (c). It could be tolerated, however, because it does not perturb the integrated power results. Voltage waveforms with rise times of longer duration (figs. 5(b) and (d)) are accurately recorded.

Gun current was sensed by a Rogowski coil (ref. 8) encircling the center electrode at the breech. A signal proportional to the time rate of change of gun current was transmitted to the screen room by a coaxial cable. The signal was then actively integrated, gain adjusted, and sent to the nearby transient digital recorder.

A two-channel transient analog-to-digital recorder accepted the gun voltage and gun current signals. It converted these signals to digital-recorded data that could be incorporated in the laboratory computing system. The digitizer is described in the appendix.

Transient spectra. - The streak spectra were obtained by coupling an image converter camera, used in streak mode, in tandem with a grating polychromator. The optical arrangement is diagrammed in figure 6, and the actual apparatus is shown in figure 4. The discharge radiation was focused by two lenses (one of which served as the gun-barrel window) on the polychromator entrance slit. The spectrum produced at the focal plane of the polychromator is viewed by the electronic image-converter camera by means of the mirror.

The polychromator used is a modification of a $\frac{1}{2}$-meter Ebert-mounting spectrometer. The exit slit was removed to permit observation of a 4-centimeter segment of the 


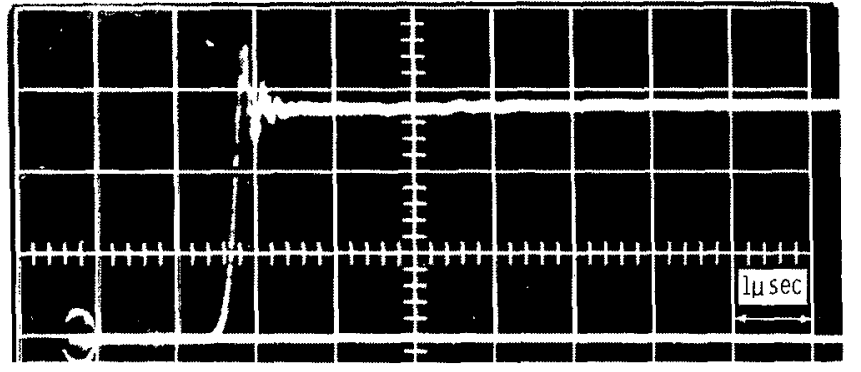

(a) Sharp-front voltage waveform. Capacitive-divider probe signal, 6.67 kilovolts per centimeter.

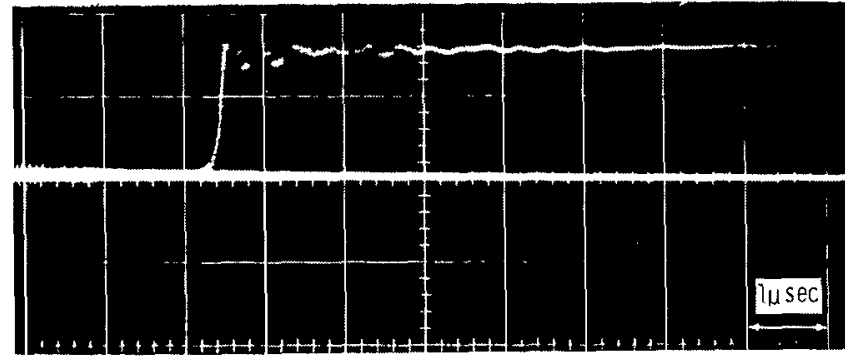

(c) Sharp-front voltage waveform. Dual-probe signal, 11.6 kilovolts per centimeter.

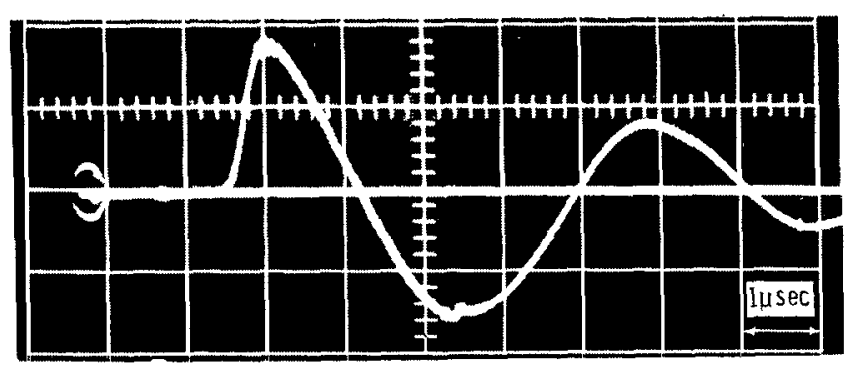

(b) Soft-front voltage waveform. Capacitive-divider probe signal, 6.67 kilovolt per centimeter.

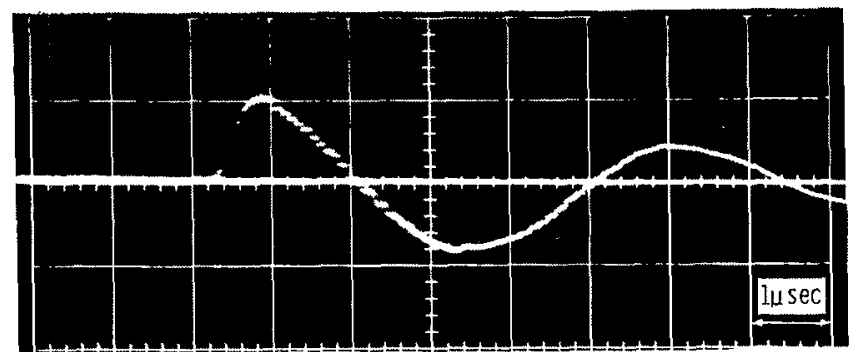

(d) Soft-front voltage waveform. Dual-probe signal, 11.6 kilovolts per centimeter.

Figure 5. - Dual-probe waveforms compared with capacitive-divider-probe waveforms. 


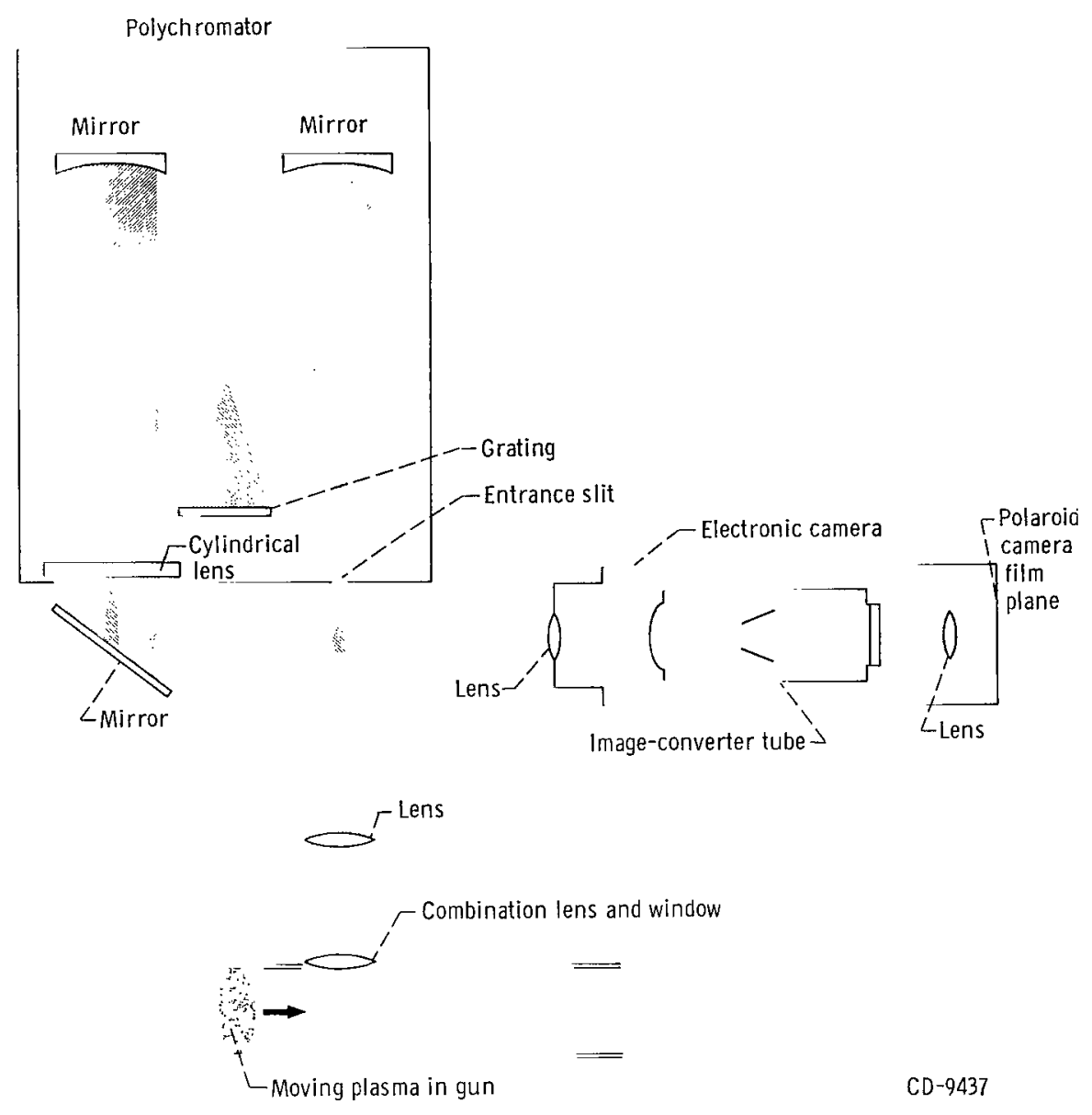

Figure 6. - Schematic drawing (top-view) of apparatus for recording transient spectra.

focal plane. A short focal length cylindrical lens (mounted axis horizontal) was installed immediately preceding the focal plane to reduce the spectral image height. The latter modification served to increase the optical speed of the system by increasing the radiant power per unit area on the image-converter tube. It also served to increase the temporal resolution of the system by providing spectral lines which were short compared with the scannable length of the converter tube.

A minor modification of the image converter camera lens was also necessary to obtain adequate spectral dispersion. The normal magnification range of the camera was considerably less than 1 . Thus, the 32-angstrom-per-millimeter (or $\times 10^{-1} \mathrm{~nm} / \mathrm{mm}$ ) reciprocal linear dispersion at the polychromator focal plane becomes hundreds of angstroms per millimeter on the Polaroid film when the normal camera lens is used. The attachment of a +3 diopter lens to the face of the camera lens, together with the use of the polychromator in second order, permitted a reciprocal linear dispersion of $70.4 \AA$ 
per millimeter to be obtained on the film record. This dispersion was adequate for the analysis of the spectra. Better dispersion could have been obtained, but its price would have been reduced optical speed.

The useable wavelength range per exposure was $250 \AA$. Wavelengths below $3800 \AA$ were not detectable because of the glass lenses in the system. The upper wavelength limit of about $5500 \AA$ was set by the spectral response characteristics of both the imageconverter tube and the film detector (Polaroid, ASA 10 000).

The camera was operated in the streak mode for a duration of 10 microseconds. Thus, a streak spectrum $250 \AA$ wide was obtained for any given shot. To survey the entire spectral range of the system thus would require seven successive shots. However, for this study the wavelength range encompassed by three successive shots provided sufficient information to permit the major constituents of the gun discharges to be identified. The camera was precisely triggered to begin its scan just before the plasma reached the viewing port. Through delay circuits the camera was synchronized with voltage application to the gun. The scan duration was monitored on an oscilloscope to permit the spectra observed to be correlated with the time scale of other gun events.

The time lapse between observed events is, of course, directly proportional to streak distance between the events. However, the fact that the spectral line viewed had a finite length limited the attainable time resolution of the streak. As recorded on the film, the spectral line image was 1.2 millimeters high, and the streak length was 28.0 millimeters. Thus, the best attainable time resolution for a single image point is

$$
\text { (Time per sweep) } \times \frac{\text { Line height }}{\text { Sweep length }}
$$

For the 10-microsecond sweep duration used, the time resolution was 0.43 microsecond.

\section{EXPERIMENTAL PROCEDURE}

The first step in the operating sequence for the experiments was to evacuate the gun and test section to low pressure $\left(10^{-6} \mathrm{~mm}\right.$ of $\mathrm{Hg}$ or $\left.10^{-8} \mathrm{~N} / \mathrm{cm}^{2}\right)$. A short-duration puff of argon propellant was then injected between the electrodes. A controlled period of time was allowed for the gas to disperse between the electrodes and for the charged capacitor bank to be switched to the gun. A time period of 1100 microseconds was based on optimum delay time (with respect to kinetic efficiency) investigated previously (ref. 1). After breakdown, the resulting plasma was accelerated out of the gun and into the evacuated test section, where it impinged on the calorimeter cup. In all reported data, the center electrode was initially negative. 
The following procedure was used to obtain gun performance for each voltage and injected mass:

(1) The mass per puff was calibrated before the series of shots.

(2) The gun was fired 10 times to outgas and condition the electrodes.

(3) All data were gathered simultaneously, and synchronously for many identical shots.

(4) The mass per puff was recalibrated.

The variation of efficiency and magnetic front velocity and mass over the practical operating range of the device was determined for three different bank voltages: 15,18 , and 20 kilovolts. The experimental gun efficiency was determined by dividing the energy received in the calorimeter cup by the original stored energy. The calorimeter cup cannot differentiate between the thermal energy and the directed kinetic energy of the impinging exhaust. The exhaust has been assumed herein to be primarily directed kinetic energy, as indicated by theoretical results of reference 1 and observation of good exhaust-beam collimation.

The transient spectra were obtained by recording a 250 - $\AA$-wide band of spectra per shot. Three similar shots were required to survey the spectral range of inter est. Near similar shots were determined from calorimeter, voltage, current, and magnetic-probe records. Each section of the composite spectral record thus corresponds to approximately the same plasma conditions.

Camera streak speeds as fast as 2 microseconds per sweep gave recordable spectra for only the most intense lines. Fully developed spectra were obtained with 10microsecond-duration sweeps, and this sweep speed was used for the spectra of this report.

\section{DEFINITION OF PERFORMANCE PARAMETERS}

\section{Analytical Parameters}

The initial derivation of the theory used herein for determining gun performance is described in reference 2. Added details and calculations for crowbarred guns with various losses are presented in reference 1. A brief description of theoretical terms is necessary before describing the results of the experiment.

The kinetic efficiency $\eta_{2}$ is defined as the ratio of the directed kinetic energy in the exhaust to the original stored energy in the capacitor bank: 


$$
\eta_{2} \equiv \frac{\frac{1}{2} M_{o}\left(\frac{d x}{d t}\right)_{x=l}^{2}}{\frac{1}{2} C V_{o}^{2}}
$$

A nondimensional exit velocity $\dot{\xi}$ is defined in reference 1 as

$$
\dot{\xi} \equiv \sqrt{\frac{L^{\prime} C}{l}}\left(\frac{d x}{d t}\right)_{x=l}
$$

where

$M_{0} \quad$ total mass swept up per shot, kg

$\mathrm{x}$ distance of current sheet from initial discharge location, $\mathrm{m}$

$\mathrm{t}$ time, sec

C capacitance of bank, $\mathrm{F}$

$\mathrm{V}_{\mathrm{O}}$ initial capacitor voltage, $\mathrm{V}$

$l$ effective gun length, $m$

$\mathrm{L}^{\prime} \quad$ gun inductance per unit length, $\mathrm{H} / \mathrm{m}$

The theoretical gun performance is a function of various nondimensional parameters. For a given gun geometry, only two of these parameters are easily varied experimentally. They are the mass loading parameter $M$ and the mass distribution parameter $\alpha$. The parameter $M$ is defined as

$$
M=\left(\frac{2 l}{L^{\prime} \mathrm{C}^{2} \mathrm{~V}_{\mathrm{o}}^{2}}\right) \mathrm{M}_{\mathrm{O}}
$$

In the theory of reference 1 , the mass distribution in the $\mathrm{x}$-direction $\mathrm{M}_{\mathrm{o}}(\mathrm{df} / \mathrm{dx})$ was so chosen that a family of distributions could be presented from a slug to a constantdensity profile. The function

$$
\mathrm{f}=1-(1-\xi)^{1 /(1-\alpha)}
$$

was used, in which $\alpha$ varies from 0 (constant density) to 1 (slug). In this report $\alpha=0.5$ was chosen to approximate the experimental distribution. 
Neutral gas-pressure profiles in the gun as a function of time were measured prior to the experiment for a geometry similar to the self-crowbarred gun. When the time delay $(1100 \mu \mathrm{sec})$ for optimum experimental efficiency and the shape of the pressure profile at that time were known, the mass distribution parameter $\alpha$ was estimated to be approximately 0.5. Pressure profiles for the noncrowbarred gun were not determined, but $\alpha=0.5$ was used for calculating the efficiency of that gun also.

Theory and experiment can best be compared by plotting the plasma velocity and kinetic efficiency as functions of the mass loading parameters for each gun. This comparison is made in the RESULTS AND DISCUSSION section for the two guns examined in this experiment.

The remaining nondimensional parameters required to calculate gun performance are discussed in references 1 and 2 . The values used herein are listed in table I.

TABLE I. - NONDIMENSIONAL PARAMETERS

[Thickness of current sheet, $0.01 \mathrm{~m}$; effective ionization potential per ion, $1.12 \times 10^{-17} \mathrm{~J}(70 \mathrm{eV})$; effective excitation potential per ion, $6.42 \times 10^{-18} \mathrm{~J}(40 \mathrm{eV})$; fraction of ions in excited state, 1.0 ; charge number of ions, 2.0 ; mean lifetime of excited state, $\left.2.5 \times 10^{-8} \mathrm{sec}.\right]$

\begin{tabular}{|c|c|c|c|c|c|c|c|c|c|c|}
\hline \multirow{3}{*}{$\begin{array}{l}\text { Gun } \\
\text { geometry }\end{array}$} & \multicolumn{10}{|c|}{ Nondimensional parameters } \\
\hline & Diffusion & Effective & Excitation & Convection & Heat- & Resis & ance & & ductance & \\
\hline & 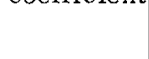 & & parameter & coefficient & parameter & Parasitic & Crowbar & Parasitic & Crowbar & Initial \\
\hline Noncrowbarred & 4.77 & $2.35 \times 10^{-3}$ & $3.06 \times 10^{-2}$ & 3.5 & $1.0 \times 10^{9}$ & 0.0517 & - & 0.398 & $-\cdots$ & 0.81 \\
\hline Self-crowbarred & 7.62 & 1.46 & 2.41 & 5.6 & $2.0 \times 10^{10}$ & .0414 & 0 & .257 & 0.01 & .17 \\
\hline
\end{tabular}

\section{Experimental Parameters}

Three experimental efficiencies are evaluated. The first is the ratio of electrical energy delivered to the gun (in time $\mathrm{T}_{\mathrm{c}}$ ) to the original stored energy:

$$
\eta_{1} \equiv \frac{\int_{0}^{\mathrm{T}_{\mathrm{c}} \mathrm{VI} d t}}{\frac{1}{2} \mathrm{CV}_{\mathrm{o}}^{2}}
$$

where

$\mathrm{V}$ gun voltage, $\mathrm{V}$ 
I gun current, $I=I(t), A$

and $\mathrm{T}_{\mathrm{c}}$ time in seconds of crowbar or first current zero (whichever is less). The value of the second experimental efficiency $\left(\eta_{2}\right)_{\exp }$ is the ratio of the energy $\mathrm{E}_{\mathrm{c}}$ received in the calorimeter cup to the original stored energy:

$$
\left(\eta_{2}\right)=\frac{\mathrm{E}_{\mathrm{c}}}{\frac{1}{2} \mathrm{CV}_{\mathrm{o}}^{2}}
$$

This efficiency is comparable to the theoretical value defined by equation (1) if the exhaust is primarily directed kinetic energy.

The third efficiency is the ratio of energy received in the calorimeter cup to the electrical energy delivered to the gun:

$$
\eta_{3} \equiv \frac{E_{c}}{\int_{0}^{\mathrm{T}} \mathrm{c} V I d t}
$$

and is the measure of losses in the gun itself.

\section{RESULTS AND DISCUSSION}

\section{Gun Performance}

The experimental and theoretical kinetic efficiencies $\eta_{2}$ and velocities determined for the two different geometries are presented as functions of the mass loading parameter in figure 7. Theoretical efficiencies are presented for both the simplified and loss models. The simplified model excludes losses due to the interaction of the plasma with the wall, and also the ionization and radiation effects. It does include ohmic losses and losses due to shock heating. The loss model includes wall drag, ionization, radiation, ohmic, and shock heating losses.

The solid symbols in figure 7 are for experimental data obtained in this investigation while transient spectral experiments were in progress. The open symbols are for data of reference 1. The data points are average values of the shots gathered.

Figure 7(a) presents data for the noncrowbarred geometry. The new efficiency data are much higher than the originally reported data but are within practical theoretical limits. A different gas baffle was employed in the new design. The transient spectra 

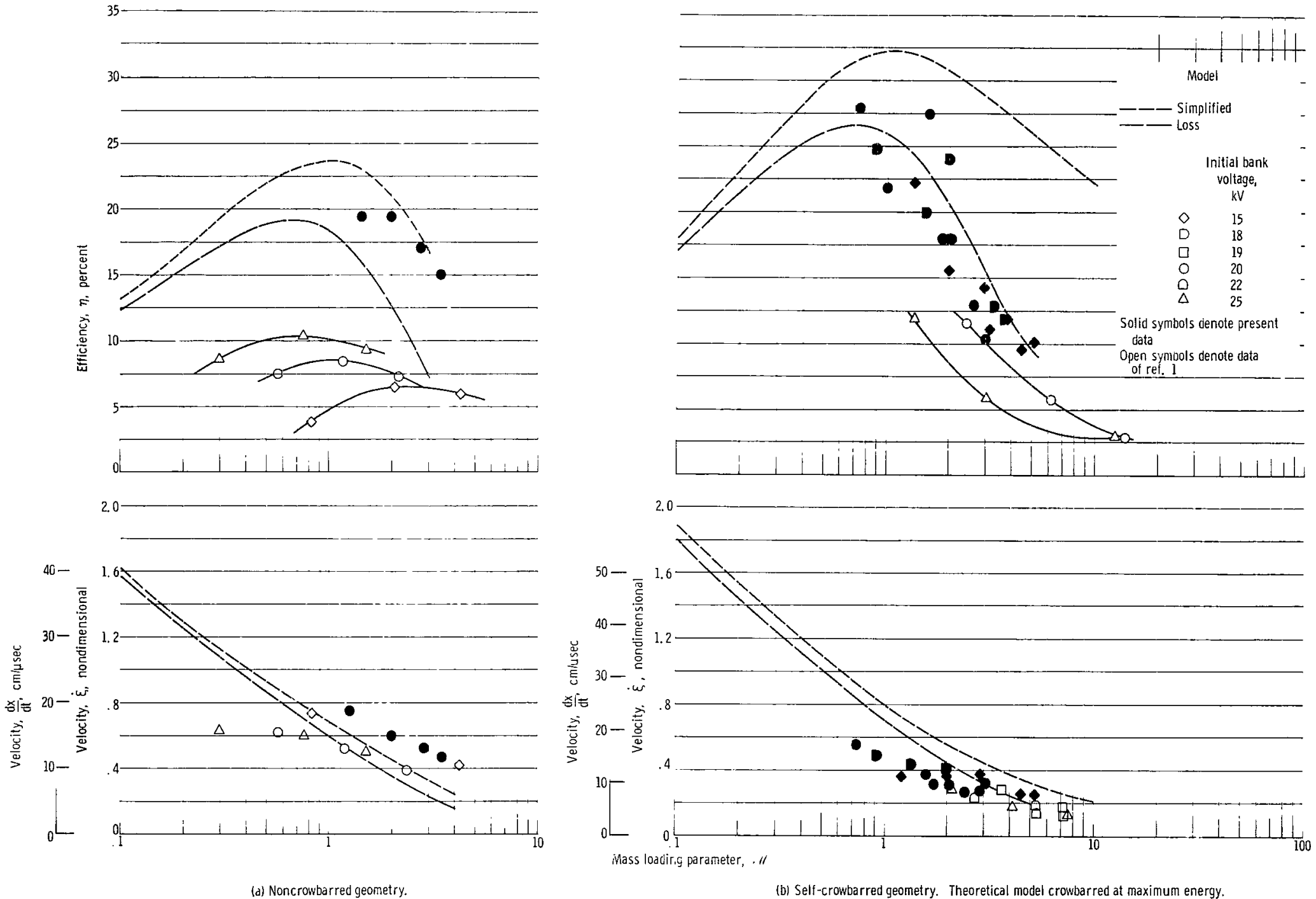

(d) Noncrowbarred geometry.

(b) Self-crowbarred geometry. Theoretical model crowbar red at maximum energy.

Figure 7. - Theoretical and experimental performance of plasma-gun geometries Mass distribution parameter, 0.5. 
show baffle contaminants in the discharge. A different amount of contaminants in the plasma could account for an $\eta$ shift in the new data. A peaked distribution of mass (contaminants) near the baffle could account for increased efficiency.

Figure 7(b) presents data for the self-crowbarred geometry. The data of reference 1 were for gas ports close to station 1 with the discharge initiating in the same location. The new data are for gas ports located at station 2 but with the main accelerating discharge initiating near the corona inhibitor ring. Therefore, the theoretical curves for geometry $\mathbf{B}$ of reference 1 are applicable provided the mass is adjusted, as has been done. The new data lie near the loss model theoretical efficiency and velocity. A new capacitor bank was used, and switch losses were not determined. The efficiency was not corrected for switch losses in the new data.

The noncrowbarred geometry was operated at $M=2.6$ for the transient spectra experiment, and the kinetic efficiency was 17 percent. The self-crowbarred geometry was operated at $M=0.72$ for the transient spectra experiment, and the kinetic efficiency

TABLE II. - SUMMARY OF EXPERIMENTAL DATA

\begin{tabular}{|c|c|c|c|c|c|c|}
\hline $\begin{array}{c}\text { Gun } \\
\text { geometry }\end{array}$ & \begin{tabular}{|c|} 
Mass \\
loading \\
parameter, \\
$\mathscr{\mu}$
\end{tabular} & $\begin{array}{c}\text { Delivered } \\
\text { power } \\
\text { efficiency, } \\
\eta_{1}\end{array}$ & $\begin{array}{c}\text { Kinetic } \\
\text { efficiency, } \\
\eta_{2}\end{array}$ & $\begin{array}{c}\text { Utilization } \\
\text { efficiency, } \\
\eta_{3}\end{array}$ & $\begin{array}{c}\text { Nondimensional } \\
\text { velocity, } \\
\dot{\xi}\end{array}$ & $\begin{array}{c}\text { Bank } \\
\text { voltage, } \\
\mathrm{V}_{\mathrm{o}} \\
\mathrm{kV}\end{array}$ \\
\hline \multirow[t]{4}{*}{ Noncrowbarred } & 1.24 & 0.55 & 0.19 & 0.34 & 0.74 & 20 \\
\hline & 1.98 & .53 & .19 & .36 & .60 & 20 \\
\hline & 2.63 & .52 & .17 & .33 & .52 & 20 \\
\hline & 3.28 & .53 & .15 & .28 & .49 & 20 \\
\hline \multirow[t]{18}{*}{ Self-crowbarred } & 0.72 & 0.40 & 0.28 & 0.72 & 0.54 & 20 \\
\hline & .89 & .43 & .25 & .58 & .48 & 18 \\
\hline & 1.07 & .47 & .21 & .46 & .43 & 20 \\
\hline & 1.27 & .39 & .22 & .57 & .38 & 15 \\
\hline & 1.33 & .47 & .20 & .43 & .43 & 18 \\
\hline & 1.58 & .37 & .28 & .76 & .38 & 20 \\
\hline & 1.72 & .46 & .18 & .39 & .31 & 20 \\
\hline & 1.91 & .44 & .16 & .37 & .36 & 15 \\
\hline & 1.94 & .37 & .24 & .65 & .42 & 18 \\
\hline & 2.11 & .45 & .18 & .40 & .28 & 18 \\
\hline & 2.50 & .36 & .13 & .36 & .27 & 20 \\
\hline & 2.80 & .37 & .14 & .38 & .36 & 15 \\
\hline & 2.86 & .34 & .11 & .32 & .24 & 20 \\
\hline & 3.06 & .44 & .11 & .26 & .29 & 15 \\
\hline & 3.09 & .36 & .13 & .36 & .29 & 18 \\
\hline & 3.55 & .39 & .12 & .30 & .26 & 18 \\
\hline & 4.46 & .36 & .10 & .28 & .27 & 15 \\
\hline & 5.12 & .39 & .11 & .28 & .26 & 15 \\
\hline
\end{tabular}


was 28 percent. Spectra were taken at these conditions for maximum luminosity and best sheet definition.

Table $I$ is a summary of the new data. The noncrowbarred geometry has a greater portion of the electrical energy delivered to. the gun terminals ( 52 to 55 percent) than has the self-crowbarred geometry ( 35 to 47 percent). Yet the noncrowbarred geometry has poorer kinetic efficiency. This result is partly explained by the fact that the moving discharge initiates near midbarrel in this geometry. The energy delivered to the gun terminals is therefore split between active and inactive portions of the barrel length. In the self-crowbarred geometry, the active portion of the barrel length is almost twice as great. The efficiency $\eta_{3}$ of utilizing the energy delivered to the gun terminals, for the self-crowbarred gun, is generally higher than the corresponding case for the noncrowbarred gun.

The data listed in table II are the mean values of many similar shots. The probable deviations from the mean value are of the order of 3 percent, which is less than the overall calibration accuracy.
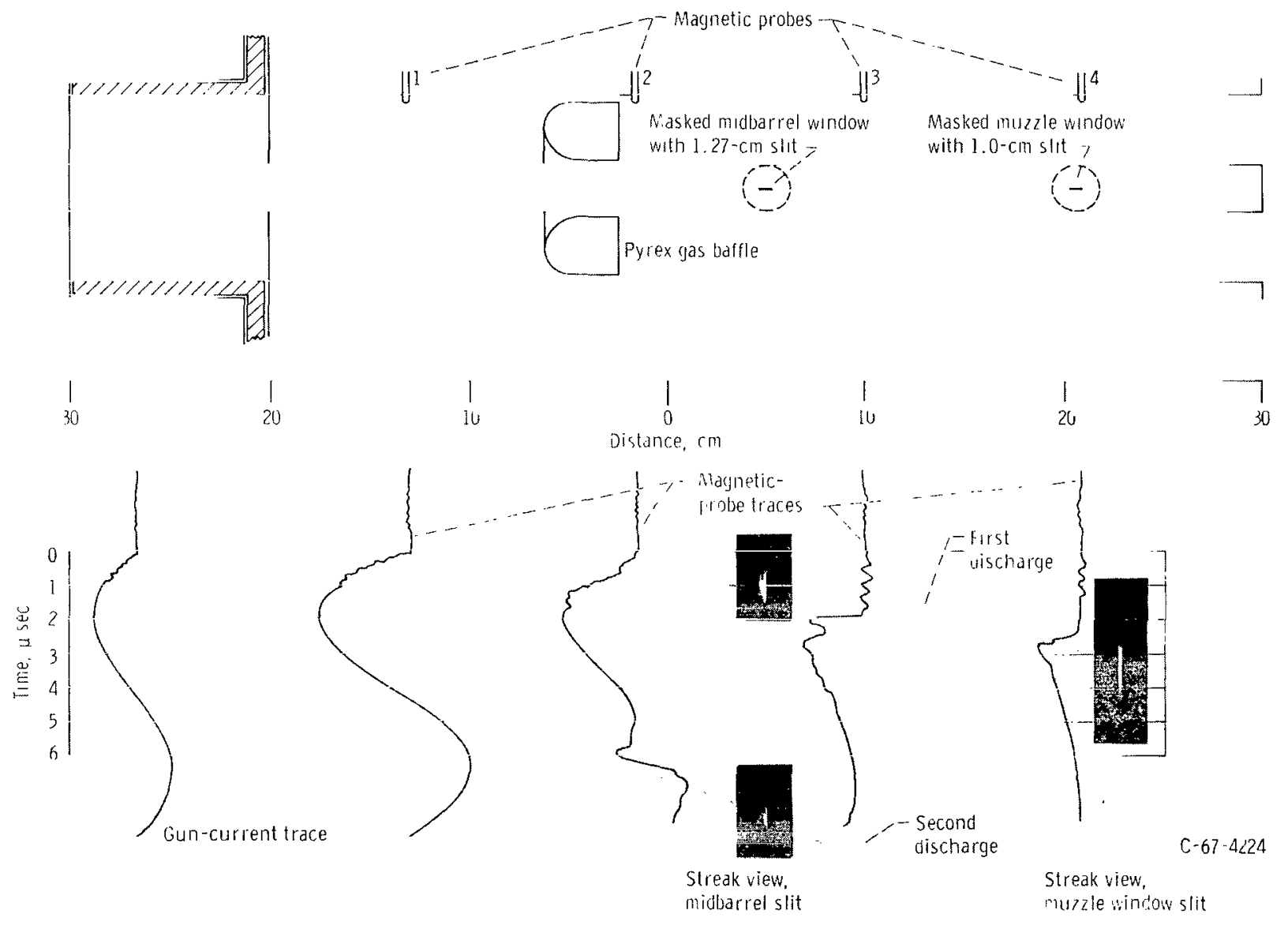

Figure 8. - Distance -time diagram of discharges in noncrowbarred gun. 


\section{Description of the Discharges in the Guns}

Noncrowbarred geometry. - Multiple moving discharges occur in the noncrowbarred geometry, each forming near the pyrex gas baffle. The secondary discharges decay before ever reaching the gun muzzle. No static discharges occur in the barrel. These conclusions are drawn from the combined examination of streak camera views and azimuthal magnetic field probe traces. Figure 8 shows these views and traces along with a distance-time diagram of the discharges.

In reference 9 the successive fronts in the gun described by Marshall carried alternate-sign gross currents. The fronts were well defined, and the azimuthal magnetic field reversed abruptly as each front passed the magnetic probe. In the present experiment the noncrowbarred gun exhibited similar characteristics. This similarity is evident in the magnetic field traces of figure 8. The gun current trace is shown to correlate the electrical events with the position of the discharges. Streak views of the discharges at the midbarrel window slit show that the first discharge formed in the vicinity of the slit and that later a second discharge moved past the slit. Streak views at the muzzle window slit show the first front with velocity of 6.0 centimeters per microsecond with a later-decaying residual light. No secondary fronts can be discerned in the presence of the residual light.

Self-crowbarred geometry. - The discharges occurring in the self-crowbarred geometry are more complicated. Both static and multiple moving discharges occur. This conclusion is drawn from a combined examination of frame and streak camera views of the discharge and azimuthal magnetic field traces. Figure 9 shows these traces and views. In this gun, the viewing port is located at midbarrel, which is the location of maximum luminosity of the first moving discharge.

In figure 9 frame views of the muzzle show that the first discharge is a symmetric (nonspoked) discharge. Figure 9 magnetic probe traces locate this discharge somewhere between stations 2 and 3. It lasts until 2.0 microseconds after gun current starts, and is never observed in the streak camera views of the midbarrel slit in figure 9 . It is probably seated on the gas port holes in the center electrode.

The second discharge to occur in the gun originates near the corona inhibitor ring. It starts about 0.2 microsecond after the start of gun current. The magnetic probe traces of figure 9 show this front progressing down the barrel. The streak photo of figure 9 shows it to be a well-defined front with a velocity of 7.1 centimeters per microsecond. It is the first front to pass the midbarrel window, and it passes at a time that can be predicted from magnetic front velocity (ref. 6). Figure 9 also shows gun voltage and current, respectively, to correlate the electrical events with the other diagnostic measurements and to estimate time of crowbar occurrence.

The second discharge is followed, about a microsecond later, by a third discharge 


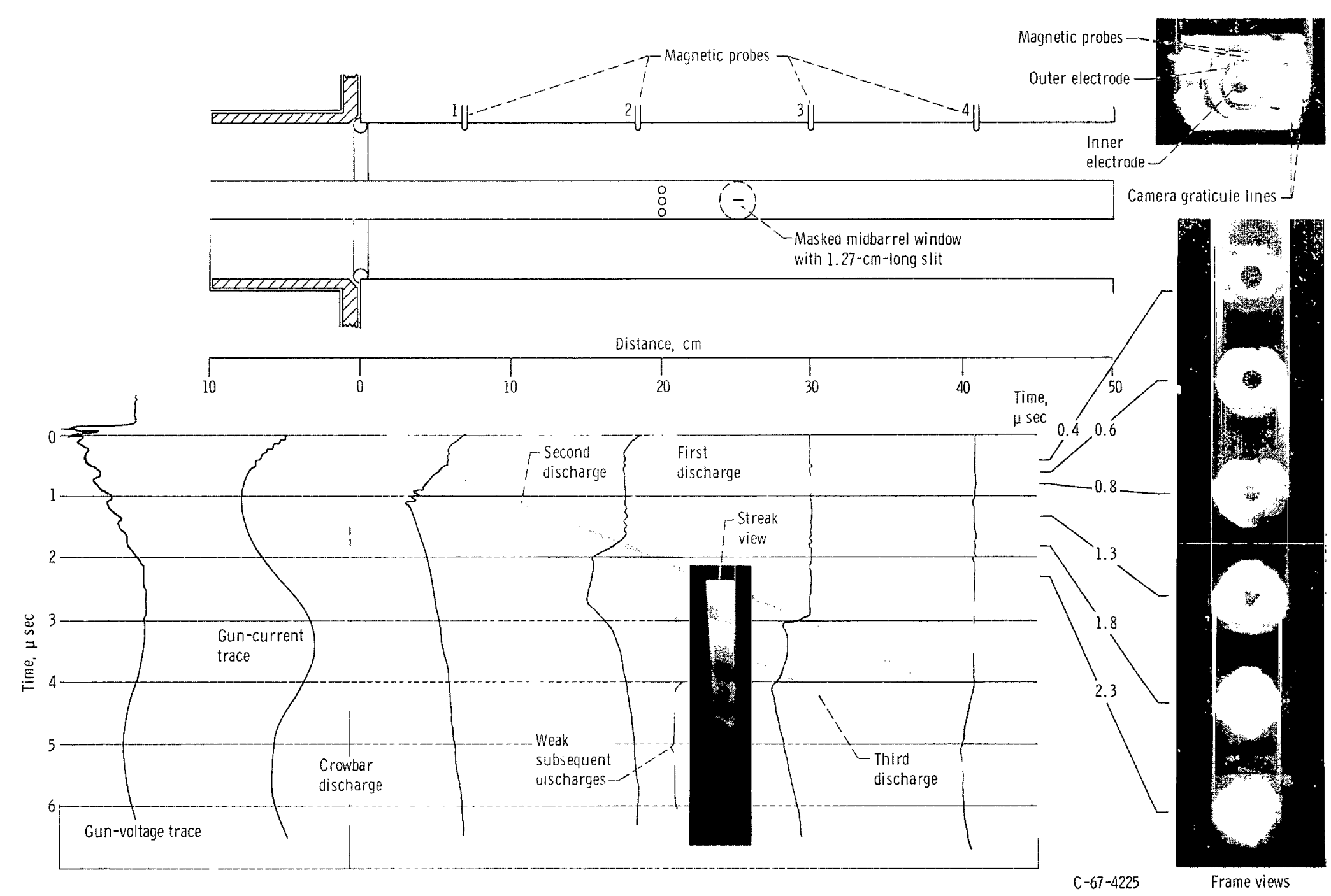

Figure 9. - Distance-time diagram of discharges in self-crowbarred gun. 
which carries less gross current. As the third discharge passes station 3, it carries current of the same polarity as the second discharge. These two fronts are driven by the "crowbarred-in" field in the gun. A static discharge at the breech acts as the crowbar switch.

The remaining minor fronts are not uniformly spaced in time, as is reported by Kvartskhava, et al. (ref. 10). No attempt is made herein to prove or to suggest a current cell-type model for the fronts, as is proposed in reference 10. These fronts were too weak to be distinguished on the probe traces.

\section{Transient Spectra}

Transient spectra of the plasma passing the muzzle window of the noncrowbarred gun are shown in figure 10. This spectra were obtained under the same conditions as for figure 8. Detailed spectral line identification was performed through a literature search of the references cited by Moore (ref. 11). Analysis of this spectra reveals that

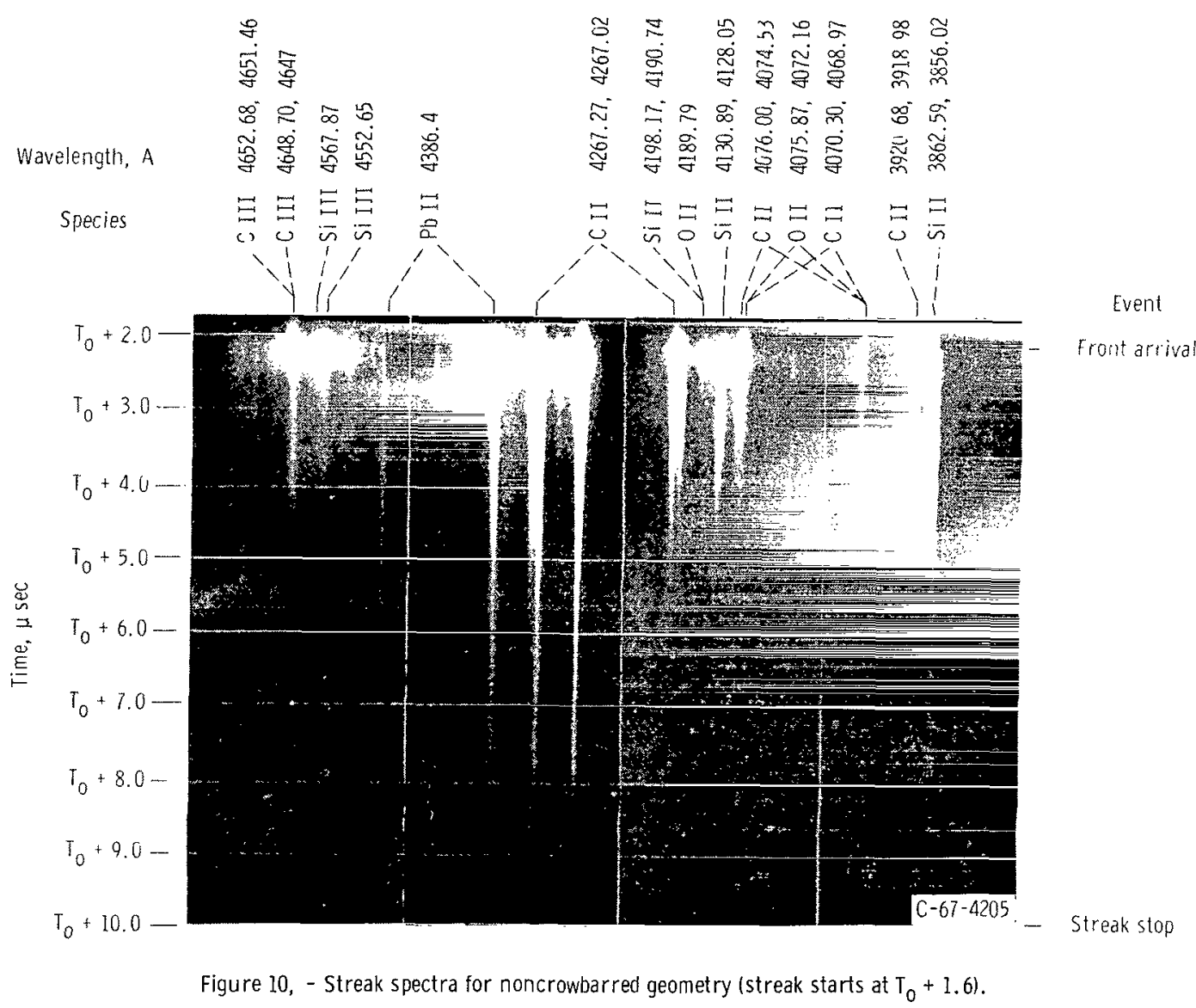


che plasma is composed primarily of singly ionized silicon and oxygen ions, with minor amounts of Si III, C II, and C III present. Spectral lines of the species Si IV, Ar I, Ar II, Cu I, and $\mathrm{Cu} I I$ were searched for but were not detected. Thus, the conclusion was reached that the plasma is supported almost wholly by the constituents of the pyrex gas baffle.

The temporal variation of the spectrum indicates that, by the time the plasma reaches the muzzle window, it consists of the main front trailed by a monatonically decaying plasma. Thus, if any multiple fronts formed upstream, they have decayed before reaching the muzzle window. A similar effect is described in reference 9 .

The spectral evidence demonstrates that the noncrowbarred geometry produces a pyrex plasma rather than the preferred argon plasma. It is probable that this results from discharge initiation across the surface of the pyrex gas baffle. Whatever the cause may be, the result is undesirable from the standpoint of correlating theory with experiment.

For the self-crowbarred mode of gun operation, the plasma was viewed at the midbarrel window. The apparatus was set up as shown in figure 4. The spectral record is presented in figure 11 for conditions similar to those described in figure 9. The three parts of figure 11 show three individual, sequential spectral records, centered around the wavelengths 3900,4150 , and $4400 \AA$, respectively. Thus, small differences in excitation level, exposure level, and time scale may exist among the three parts of the figure.

Higher resolution non-time-resolved exposures were subsequently made under gun conditions matching those of the streak spectra to permit unequivocal identification of the species present in the discharge. These auxiliary spectra are presented above the streak spectra in figure 11, and each is the total integrated record of 10 gun shots. The reciprocal linear dispersion of these auxiliary spectra was $16.2 \AA$ per millimeter. The same polychromator was used, and in the same grating order, as for the streak shots. The difference was that the film housing of a Polaroid camera was mounted at the polychromator focal plane to record the spectra. In the process of reproducing and magnifying the spectra for the report, some of the weaker lines were lost, but the wavelengths are listed in the figure. A magnifying eyepiece used on the original records, along with a knowledge of the relative location of expected spectral lines, allowed evaluation of when a given line occurred in the series of discharges in a gun shot. In figure 11, the particular discharge in which each spectral line was found is indicated. However, the first discharge to occur in the gun never moves past the viewing window and therefore is not presented in figure 11. The second discharge to occur in the gun is the first moving plasma front shown in figure 11.

Consider now the spectrum of the first moving plasma front (second discharge) in figure 11. Reference to the auxiliary spectrum reveals that the first moving front spec- 

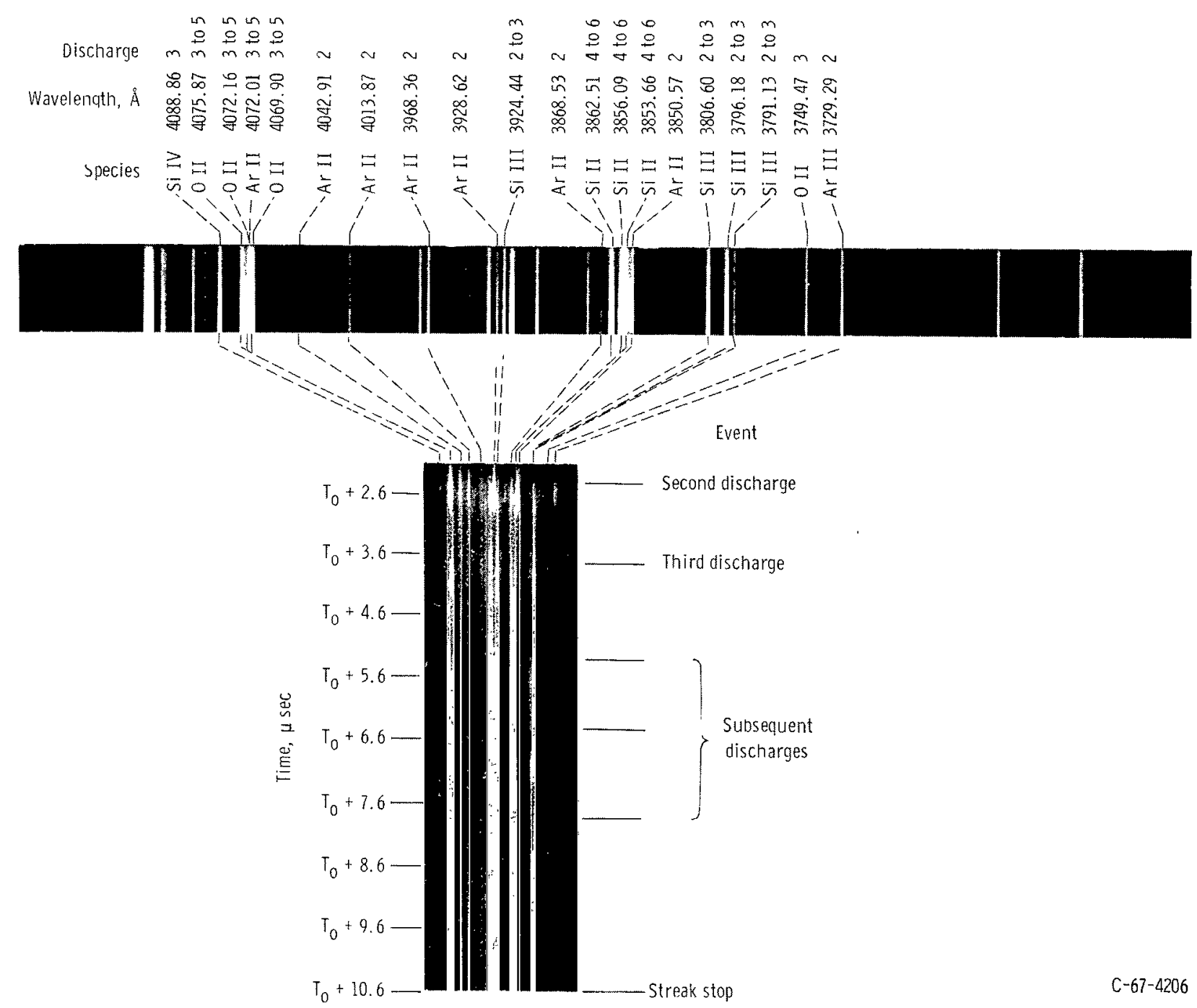

(a) Central wavelength, $3900 \AA$.

Figure 11. - Self-crowbarred gun spectra. 


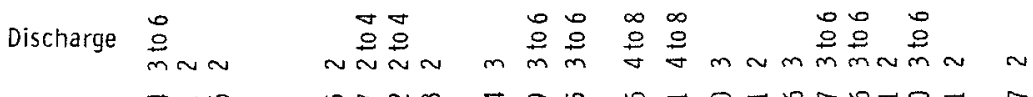

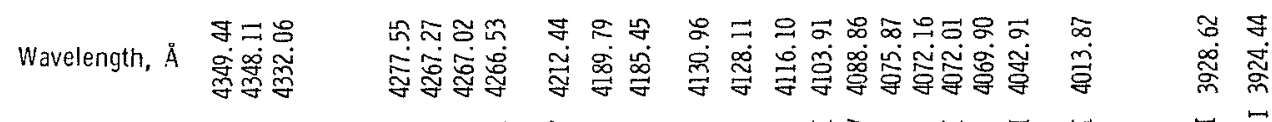

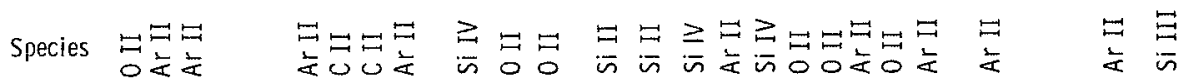
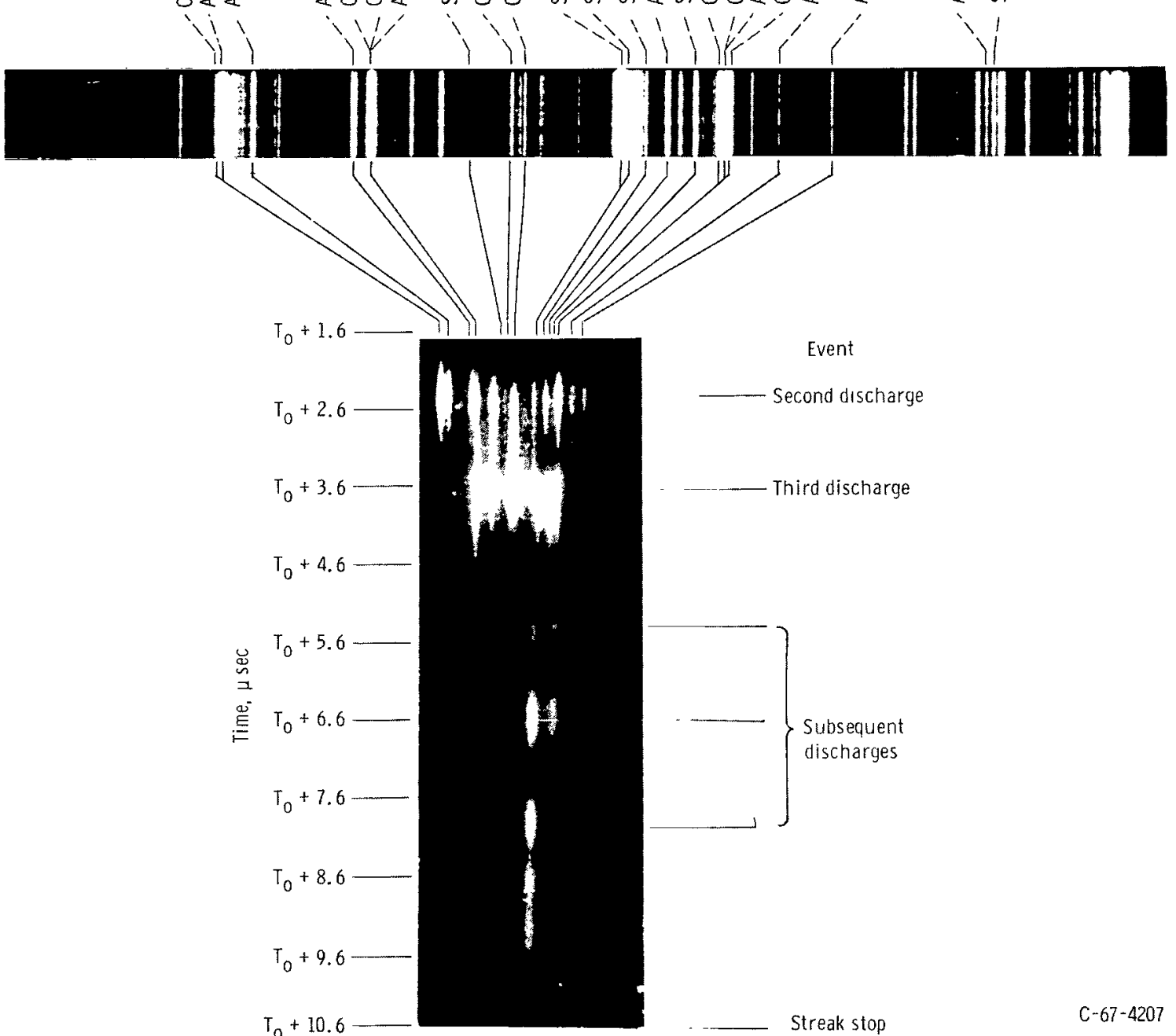

$C-67-4207$

(b) Central wavelength, $4150 \AA$ (streak starts at $\mathrm{T}_{0}+0.6$ ).

Figure 11. - Continued. 


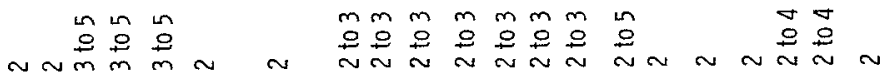

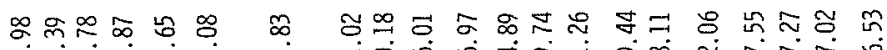

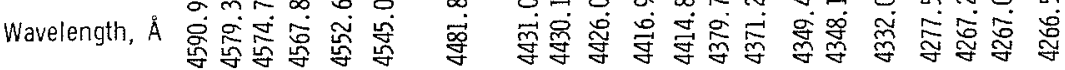

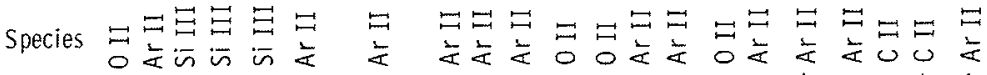
'ilí'
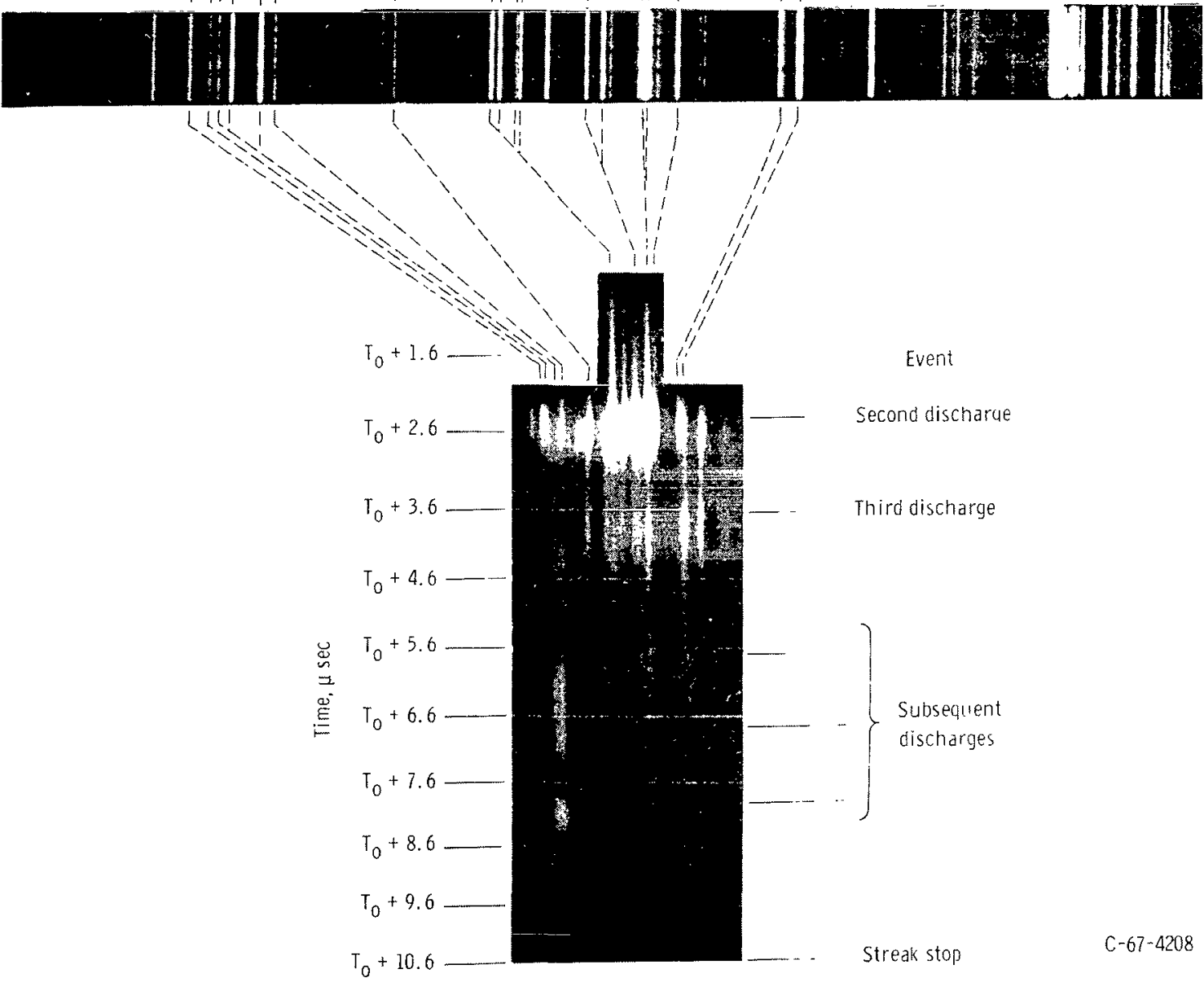

(c) Central wavelength, $4400 \AA$ (streak starts at $T_{0}+0.6$ ).

Figure 11. - Concluded. 
trum consists of a fully developed Ar II spectrum, with faint traces of Ar III lines visible on the original records. No Ar I lines were detected, but Si III and Si IV appear weakly. Thus, the first front is an energetic argon discharge containing some silica contaminant.

The second moving front (third discharge) is a mixture of Si III and Si IV, with the O II spectrum beginning to rise. Neither Ar I'nor Ar II are observed. The second moving front is basically an energetic silica discharge.

The third and subsequent moving fronts (fourth and subsequent discharges) are primarily Si II, Si III, and O II and are reminiscent of the noncrowbarred geometry spectrum shown in figure 10. These latter fronts are thus lower-energy versions of the second front.

No lines of $\mathrm{Cu} \mathrm{I}$ or $\mathrm{Cu} \mathrm{II}$ were detected in either the streak or the auxiliary spectra, which is notable since the electrodes are made of pure electrolytic copper. Were copper present in the third and subsequent moving fronts, $\mathrm{Cu} I I$ lines would have been observed, since the excitation level in these fronts is in the range of $\mathrm{Cu} \amalg$. However, any copper present in the first and second moving fronts would not have been detected, since the excitation level in these fronts would have been compatible with $\mathrm{Cu} \mathrm{IV}$ and $\mathrm{Cu} \mathrm{V}$. However, a literature search failed to uncover any study of the spectra of these species. Careful scrutiny of figures 11 (a) to (e). reveals a singular group of spectral lines in the first and second moving fronts of markedly different time behavior from the rest. These spectral lines occur at $3796,3922,3944,4131,4171,4178$, and $4229 \AA$. These lines appear about 0.3 microsecond behind Ar $\Pi$ in the first moving front and persist with nearly constant intensity through the second front. This markedly similar behavior suggests that all lines arise from the same species, which has not yet been identified. Since at least a little copper usually appears from discharges of megampere proportions between copper electrodes, these lines might be components of the spectrum of $\mathrm{Cu} \mathrm{IV}$ or $\mathrm{Cu} \mathrm{V}$. It is worthy of note that argon neutrals were undetectable not only in the second discharge, but in all other discharges as well. Indeed, no lines of neutral species of any element were observed in this study.

\section{Correlation of Spectra and Performance}

The spectral analysis results are useful in interpreting the performance comparisons shown in figure 7 . The theory predicts the kinetic efficiency for snowplow sweepup of mass distributed in a known manner along the barrel. The experimental spectra of the noncrowbarred gun show that the primary moving discharge is composed of contaminants from the gas baffle. The amount and distribution of contaminant propellant are not known. It is therefore understandable that experimental efficiencies appear to be too 
high. It is also understandable that this experiment does not agree with earlier tests of a roughly similar geometry. Minor changes in the baffle material-and location probably result in changes in the contaminant amount and distribution. Both of these effects seriously influence the theoretical kinetic efficiency.

The spectra of the self-crowbarred gun show that argon is the major constituent in the primary moving discharge. The theory only accounts for what is swept up in the primary moving discharge, with crowbar effects included. It agrees with experiment and earlier work.

\section{CONCLUDING REMARKS}

The transient spectra for two different gun geometries using argon propellant have been obtained. The spectra along with frame and streak views of the gun discharge and azimuthal magnetic field probe measurements have helped to clarify correlation of theory with experiment for the two geometries.

The self-crowbarred geometry, which exhibits relatively uncontaminated fully ionized argon spectra, shows good performance reproducibility with earlier data. New data correlate well with the theory described by Michels and Johansen (ref. 1). Spectral identification shows that the first moving front in the gun consists of a fully developed Ar II spectrum with faint Ar III lines. No neutral lines are present, but Si III and Si IV appear weakly. The second moving front is basically an energetic silica discharge. The remaining fronts are contaminant laden, with much less intensity. No electrode material was noted in the plasma in the wavelength region observed. The spectra confirm that most of the propellant in the first moving front is fully ionized argon with minor residual argon left after it passes. This helps support the observed good correlation with theory. Streak and frame views of the discharge in conjunction with magnetic field measurements in the barrel help establish a proposed multiple front model of the operation of the gun.

In contrast, for the noncrowbarred geometry, the first moving plasma front consists primarily of the constituents of the pyrex gas baffle placed near the gas ports. The spectrum shows no argon propellant lines in the wavelength region observed. Understandably, this geometry would not be expected to accurately follow the theory proposed, and it does not. The magnetic probes show that several moving discharges are present, but the secondary fronts have decayed by the time the discharge is viewed at the muzzle window. The transient spectra show a single persistent front. The per- 
formance does not agree with earlier tests of a quite similar geometry. The difference in geometry was in the placing, shape, and type of material used for the gas baffle behind the gas ports.

\section{Lewis Research Center,}

National Aeronautics and Space Administration, Cleveland, Ohio, October 11, 1967, 129-01-05-14-22. 


\section{APPENDIX - TRANSIENT DIGITAL RECORDER}

In earlier investigations (refs. 1 to 3), experimental performance of the gun was obtained by tedious and time-consuming manual data processing of oscilloscope trace photographs. Position and time surveys and gradient calculations of such surveys for any plasma measurement (electric-field, magnetic-field, particle velocity and energy, and species determinations) were too time consuming and sensitive to manual computing errors to be attempted. Specifications were written for a two-channel transient analog-todigital recorder to record data precisely for later incorporation in available laboratory automatic data processing and computing systems. The system was constructed by a contractor, specification checked at Lewis, and then applied to the present experiment.

The transient digital recorder has the capability of digitizing two analog voltage inputs at a maximum rate of 5 million samples per second. The recorder stores as many as 500 samples of acquired data from each of the two inputs. The stored digitized samples can be reconstructed to their analog form and presented on an oscilloscope. This method provides a "quick-look" display of the analog signals recorded by the operator. The stored digital data can be punched out on paper tape for later use in a computing system.

Each input channel has a wideband precision amplifier (with dc offset capability) to convert the analog input signal $( \pm 0.750 \mathrm{~V})$ to a unidirectional signal (0 to $10.0 \mathrm{~V})$. Each channel has a high-speed analog-to-digital converter which converts the unidirectional signal to a binary-coded digit (seven bits) every 200 nanoseconds.

The traveling-wave-type analog-to-digital converter used in each input channel utilizes a signal comparator for each bit of its output code, seven comparators in total per channel. That is, one comparator is used to determine each of the $2^{6}, 2^{5}, 2^{4}, 2^{3}, 2^{2}$, $2^{1}$, and $2^{0}$ weight decisions.

The input analog signal is brought to the comparators through an input delay line in the digitizer. Each comparator is connected to a tap on the input delay line. The delay line taps are spaced 200 nanoseconds apart. The $2^{6}$ weight comparator is connected to the input of the delay line. The $2^{5}$ weight comparator is connected to the next tap so that it receives the leading edge of the input signal 200 nanoseconds later. Likewise, the other comparators are arranged by order of weight, 200 nanoseconds apart along the delay line. Finally, the $2^{0}$ weight comparator receives the leading edge of the input analog voltage waveform delayed by 1200 nanoseconds. The end of the delay line is terminated in its characteristic impedance to prevent reflections. Hence, the leading edge of the input signal is presented sequentially (every $200 \mathrm{nsec}$ ) to seven comparators. A precision 5-megacycle-per-second clock controls the strobe-like action of the comparators. By the time the leading edge of the input waveform has reached the $2^{0}$ comparator, seven separate bit decisions have been determined controlled by seven consecutive clock pulses. 
To make a correct decision, each comparator must "know" the previous bit decisions, properly delayed in time, along with the input signal level. By the time the $2^{0}$ weight decision has been made, that comparator has all six previous bit decisions available. The seven decisions on digitizing the leading edge of the analog input signal are now sent to a 500-word memory. After 200 nanoseconds, the next decisions are sent to the memory. The waveform, at the next time increment after the leading edge, has been "read". The memory is capable of storing 500 of these words for each channel. The memory (for each bit) is a glass delay line (100- $\mu$ sec delay). Once stored, the data is constantly recirculated and is available for many hours.

The data contained in the circulating memory are sampled by a digital-to-analog converter, and the reconstructed analog signal is displayed on the system oscilloscope. When requested by the operator, the system will punch out on paper tape all the data contained in the memory, in the same sequence that it was collected. First, six words of predata instructions are punched on the tape. These instructions serve to identify the experiment, the run number, the type of computing to be performed, and various calibration and scale factors for each channel. Then the data, which have been stored in the

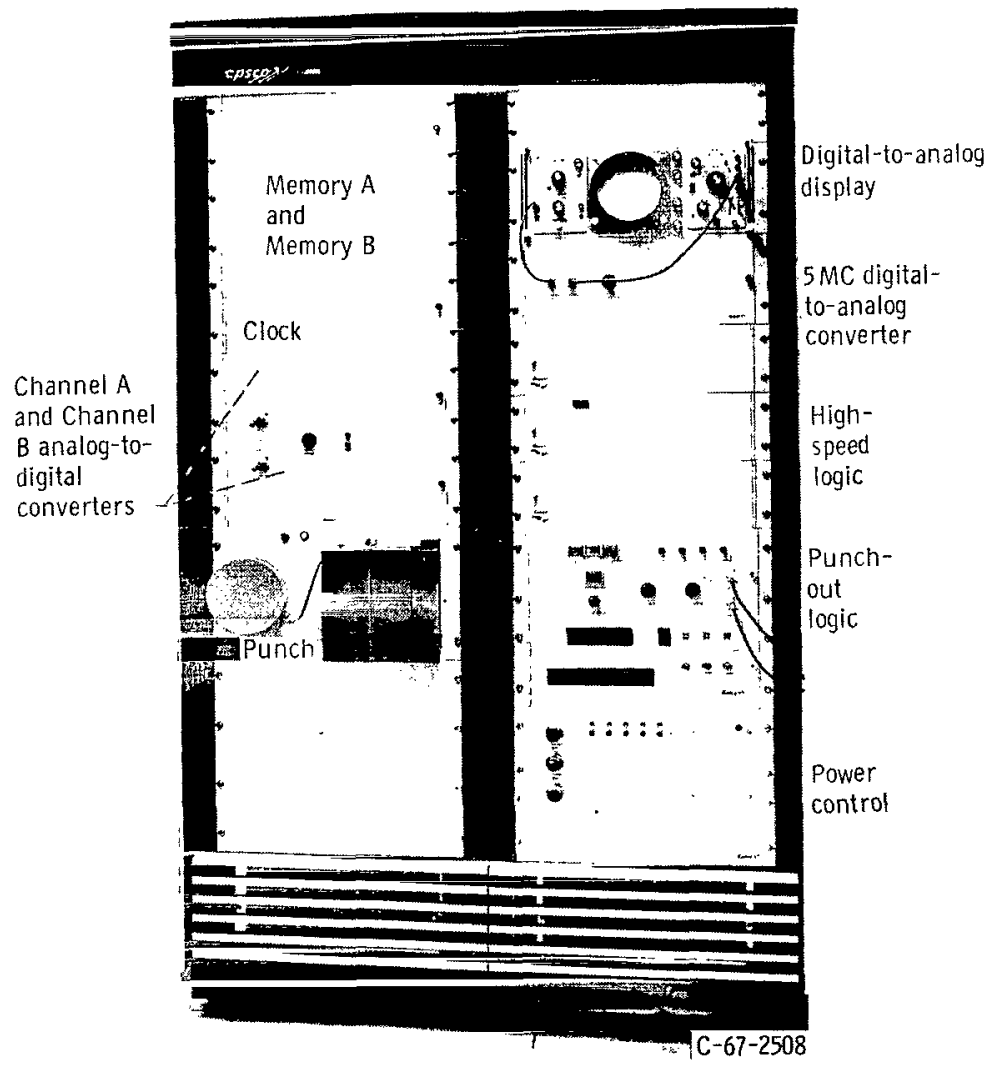

Figure 12. - High-speed data-acquisition system. 
memory in binary-word form, are converted to binary-coded decimal form and punched on the tape in predetermined format.

When the system "clear" switch is activated by the operator, all data in the system are "erased", and the system is ready to gather new data. New data are acquired by an external START signal from the experiment. A STOP signal can be externally applied to the system so that the system does not punch out any more data than is required. Provision is also made for threshold-detector start, which automatically starts the recorder when the input signal on one channel reaches the preset (threshold) level. The system is shown in figure 12. System characteristics are as follows:

(1) Zero drift and noise are less than one bit.

(2) Gain accuracy or deviation of the average value from the correct value is less than $\pm 0.78+0.02 \Delta \mathrm{T}$ percent of full scale.

(3) Linearity is within \pm 0.056 percent of full scale for the best straight line.

(4) Standard deviation from linearity is less than one bit.

(5) Time-slot registration for an 80-kilocycle-per-second triangular wave applied to both channels simultaneously recorded in each channel for the same time slot is the same for 95 percent of all samples. A difference of not more than one bit is permitted for the remaining 5 percent of samples.

(6) To determine settling time, a precision 500-kilocycle-per-second square wave (rise time less than $20 \mathrm{nsec}$ ) was recorded. The output data consists of five-word trains (of alternate polarity), the last four words of which meet the gain accuracy requirements.

(7) Conversion rates are 5, 2.5, 1.25, and 0.625 megasamples per second.

(8) Input voltage range is -0.75 to 0.75 volts, full scale.

(9) Input impedance is 5000 ohms.

(10) Word structure is 6 bits plus sign, binary.

(11) Aperture time is 25 to 50 nanoseconds. 


\section{REFERENCES}

1. Michels, Charles J.; and Johansen, Albert E.: Experimental and Theoretical Performance of Coaxial Plasma Guns. NASA TN D-3469, 1966.

2. Michels, C. J.; Heighway, J. E. ; and Johansen, A. E. : Analytical and Experimental Performance of Capacitor Powered Coaxial Plasma Guns. AIAA J., vol. 4, no. 5, May 1966, pp. 823-830.

3. Michels, Charles J.; and Ramins, Peter: Performance of Coaxial Plasma Gun with Various Propellant. Phys. Fluids, vol. 7, no. 11, pt. 2, Nov. 1964, pp. S71-S74.

4. Michels, Charles J.: Some Transient Electrical Characteristics of the Exhaust of a Self-Crowbarred Coaxial Plasma Gun. NASA TN D-2571, 1965.

5. Michels, Charles J.; and Terdan, Fred F.: Characteristics of a 5-Kilojoule, Ignitron-Switched, Fast-Capacitor Bank. NASA TN D-2808, 1965.

6. Dike, R. S. ; and Kemp, E. L.: Design of a Low Inductance Capacitor and Switch Assembly. Rev. Sci. Instr., vol. 35, no. 4, Apr. 1964, pp. 516-517.

7. Moses, Kenneth G. ; and Korneff, Theodore: Voltage Measurements in the Presence of Strong Fields. Rev. Sci. Instr., vol. 34, no. 8, Aug. 1963, pp. 849-853.

8. Glasstone, Samuel; and Lovberg, Ralph H.: Controlled Thermonuclear Reactions.

D. Van Nostrand Co., Inc., 1960, pp. 164-165.

9. Marshall, J.: Hydromagnetic Plasma Gun. Plasma Acceleration. Sidney W. Kash, ed., Stanford University Press, 1960, pp. 60-72.

10. Kvartskhava, I. F.; Meladze, R. D. ; Khautiev, E. Yu.; Reshetnyak, N. G.; and Sinyavskii, A. P.: Limitation on Plasmoid Velocity in Railsotron Devices. Soviet Phys. - Tech. Phys., vol. 11, no. 4, Oct. 1966, pp. 564-566.

11. Moore, Charlotte E.: Atomic Energy Levels as Derived from the Analyses of Optical Spectra. Circ. No. 467, vol. 1, National Bureau of Standards, June 15, 1949. 


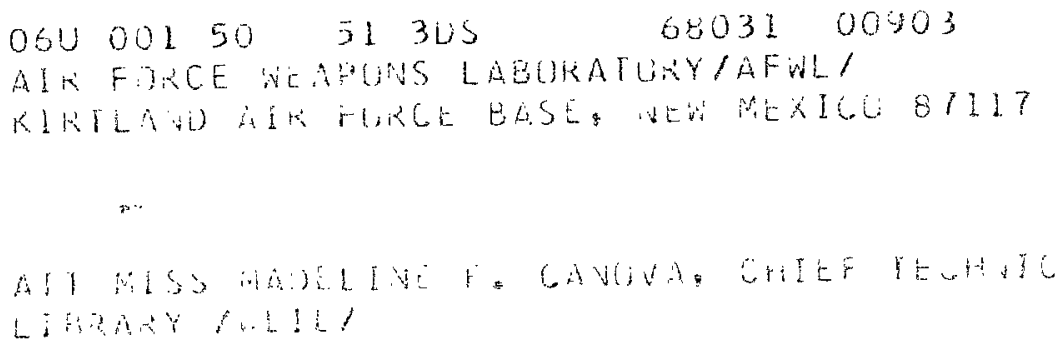

"The aeronautical and space activities of the United States shall be conducted so as to contribute ... to the expansion of buman knowledge of phenomena in the atmospbere and space. The Administration sball provide for the widest practicable and appropriate dissemination of information concerning its activities and the results thereof."

-National Aeronautics and Spack ACt of 1958

\section{NASA SCIENTIFIC AND TECHNICAL PUBLICATIONS}

TECHNICAL REPORTS: Scientific and technical information considered important, complete, and a lasting contribution to existing knowledge.

TECHNICAL NOTES: Information less broad in scope but nevertheless of importance as a contribution to existing knowledge.

TECHNICAL MEMORANDUMS: Information receiving limited distribution because of preliminary data, security classification, or other reasons.

CONTRACTOR REPORTS: Scientific and technical information generated under a NASA contract or grant and considered an important contribution to existing knowledge.

TECHNICAL TRANSLATIONS: Information published in a foreign language considered to merit NASA distribution in English.

SPECIAL PUBLICATIONS: Information derived from or of value to NASA activities. Publications include conference proceedings, monographs, data compilations, handbooks, sourcebooks, and special bibliographies.

TECHNOLOGY UTILIZATION PUBLICATIONS: Information on technology used by NASA that may be of particular interest in commercial and other non-aerospace applications. Publications include Tech Briefs, Technology Utilization Reports and Notes, and Technology Surveys.

Details on the availability of these publications may be obtained from:

SCIENTIFIC AND TECHNICAL INFORMATION DIVISION

NATIONAL AERONAUTICS AND SPACE ADMINISTRATION

Washington, D.C. 20546 